\title{
DESDE LA BARCA: VERSOS ÚLTIMOS DE FRANCISCO BRINES
}

\section{DESDE LA BARCA: LATEST VERSES BY FRANCISCO BRINES}

\author{
Marcela Romano \\ Universidad Nacional de Mar del Plata
}

Resumen: Este artículo se detiene en los poemas últimos de Francisco Brines, publicados en la plaquette Elegías a M. B. (2010) y en Donde muere la muerte, colección incorporada a la antología consultada realizada por Alejandro Duque Amusco (2017). Estos textos, cuya retracción formal da cuenta de la inminencia de una poética del final, no son sino otra sostenida variación de la melodía esencial que atraviesa desde el principio el proyecto creador brineano: la despedida una y otra vez ensayada, iluminada por ramalazos de empecinado vitalismo.

Palabras clave: poesía española; Francisco Brines; Elegías a M. B.; Donde muere la muerte.

Aвstract: This article focuses on the latest poems by Francisco Brines, published in the plaquette Elegías a M. B. (2010) and Donde muere la muerte, a collection incorporated into the consulted anthology made by Alejandro Duque Amusco (2017). These texts, whose formal retraction presents the imminence of a closing poetics, are a sustained variation of the essential melody that runs through the Brinean creative project from the beginning: the perpetual farewell illuminated by a stubborn vitalism.

KeY WORDs: Spanish poetry; Francisco Brines; Elegías a M. B.; Donde muere la muerte. 
En homenaje al poeta y al maestro, pero, sobre todo, al hombre bueno que fue Paco Brines.

Para muchos, el acercamiento a la poesía de Francisco Brines podría sintetizarse en el relato de una experiencia de lectura "extrañada», para decirlo con los formalistas rusos. Insertos todavía como estamos en la «tradición de la ruptura» de la que extensamente ha hablado Octavio Paz, o bien familiarizados, de igual modo, con poéticas que ensayan la imitatio del discurso conversacional o la parquedad de (cierta) prosa en clave objetivista, minimalista, difusamente «experiencial», hiperrealista y "sucia», la poesía de Brines genera, en efecto, «extrañamiento». En ella, el sabor de lo antiguo del que hablaban los tratadistas del Renacimiento recupera el gesto de la meditación y el autoanálisis característicos de gran parte del legado grecolatino y del Siglo de Oro español, así como los largos excursos reflexivos del Romanticismo (preferentemente inglés) ejercitado en la continuidad simbolista por Antonio Machado y leído por Unamuno y más tarde por Cernuda en Inglaterra y en América.

Así, sus críticos han hablado de Brines como «un clásico viviente» (Siles, 2002) cuya escritura resulta, asegura Gómez Toré, de «la voluntad clásica que aúna arte poética y arte de vivir» (2002:159). Esta «voluntad clásica» es directamente deudora de un imaginario de larga duración, la humanitas hispana, esa suerte de clasicismo vernáculo que, como ha visto en un notable ensayo Javier García Gibert, sumó productivamente a la «tradición de tradiciones» la vitalidad sombría del barroco español. Según el autor, en el siglo xviı, España enriquece este imaginario merced a la «meditada conversión [de la sabiduría renacentista] en sabiduría barroca del desengaño», donde «el saber y la belleza que son derrotados en el orden de la Historia pueden ser salvados o resucitados por la literatura» (García Gibert, 2002: 10-12). En este paradigma ingresa el ethos docente de Brines con su ars amandi, su ars vivendi y su ars moriendi, desbordando en la cartografía completa de su obra y en el ejercicio público de un magisterio reconocido desde siempre y galardonado, al final de sus días, con el Premio Cervantes.

La pertinaz vocación docente de la poesía de Brines nos pone frente a la pizarra las tensiones del vivir. De la reflexión elegíaca al vitalismo trágico (Andújar Almansa, 2003), de la mirada crepuscular o decididamente nocturna (Cañas, 1984) y la ontología del sufrimiento (Martín, 1998) a la epifanía feliz de los cuerpos y de 
la naturaleza, sus textos condensan una voz saturada de preguntas enormes y, a cambio, escasas respuestas: poesía del "pensamiento", al cabo, que se elabora desde un no saber, también desde un no creer, pero que acuerda, más allá de las derrotas, y precisamente por ellas, con la obligación del gozar. Los jirones de la vida ocupan privilegiadamente el escenario de la obra brineana, en la que el tiempo, la ausencia del dios, el olvido y el engaño son los personajes fundamentales. Sin embargo, los contrapuntes emergen como espléndidos antagonistas: los ojos y los cuerpos deseados y vividos con intensidad agónica, esa cuna insobornable que es la naturaleza mediterránea de la finca natal (Elca), los viajes, el placer de la cultura, el implícito diálogo con el lector.

Este trabajo se detendrá en los versos últimos de Brines, distribuidos provisoriamente en dos colecciones: Elegías a M. B., publicada por el Centro Cultural Generación del 27 en 2010, y los poemas recogidos por Alejandro Duque Amusco en su antología consultada Entre dos nadas, de 2017, donde aparece un «libro inédito» titulado allí Donde muere la muerte ${ }^{1}$. Ambas no son sino otra sostenida variación de la melodía esencial que atraviesa desde el principio el proyecto creador brineano: la despedida una y otra vez ensayada, iluminada por ramalazos de empecinado vitalismo.

\section{MADRE, DEVUÉLVEME MI BESO}

En Elegías a M. B., de 2010, plaquette con textos éditos e inéditos de Brines, el «caso lamentable» (como se nombraba en el Quinientos el motivo del planto fúnebre) gira en torno a un eje fundamental: la memoria «dolorida» de «M. B.» (María Bañó, la madre del autor). Esta muerte, entrevista en principio como amenaza cierta y luego sucedida, es el disparador de una serie de asedios a la tradición barroca y a su tópica desasida del mundo, en una «emocionante tensión

1 Escribiendo este artículo, nos llega la noticia del inminente lanzamiento del libro (mes de octubre) por la editorial Tusquets. Dado que el mismo seguramente contendrá más textos que los aquí analizados, nuestra aproximación resultará, indefectiblemente, incompleta y provisional. Quiero agradecer al coordinador de este dossier, Francisco Díaz de Castro, y a la directora de la Fundación Brines, Àngels Gregori Parra, el haberme socorrido de diversos modos para un más preciso acercamiento a estos versos últimos. 
amorosa» (Díaz de Castro, 2011: 49) que recupera la escritura de la ausencia, la elegía, en sus episodios más significativos.

La conceptualización de la elegía ofrece desafios en su andadura histórica sumamente eficaces a la hora de comprender las variables de una "estructura de sentimiento» epocal (Williams, 2000: 151) que en sus discursos excede lo meramente formal para anidar, más apropiadamente, en la elaboración de un «tono» (Romano, 2017). Entre la vieja elegía griega funeral (repuesta en la Edad Media) y la moderna elegía (que recoge operatorias de la elegía erótica latina, la renacentista, la barroca y la romántica) advertimos ya a finales del siglo Xvi un «incierto devenir» (López Bueno, 1996: 133). Según López Bueno, la elegía «tiene sus señas de identidad en la lamentación melancólica y nostálgica, que se manifiesta tanto en el tema (la ausencia y la pérdida) como en la actitud del emisor (dolorida o "miserable") y en la implicación requerida del recepton intra y/o extradiegético (1996: 136; subrayados nuestros).

Complementariamente, en pos de la comprensión de la elegía moderna, y, con ello, de los alcances del ethos elegíaco brineano, resulta crucial el fino análisis de Pedro Ruiz Pérez, quien remarca el pasaje, en el siglo XviI, de la elegía sometida a una «estricta codificación genérica» al «espacio tonal de lo elegíaco» (1996: 318). Ello auspicia, según Ruiz Pérez, «la irrupción definitiva del yo, la expresión lírica de la subjetividad, el sentimiento de la pérdida, el espacio de la memoria, el discurso, en suma, de la melancolía» (1996: 325-326). El tono «élego» que habilita para el género un campo de filiaciones más laxo que en el siglo xvi, colocándolo por encima de una combinatoria limitada de ciertas variables compositivas, retóricas y pragmáticas, recupera la intimidad de la elegía clásica más allá del elogio funeral concerniente al ámbito público y se proyecta decisivamente en la poesía contemporánea (1996: 361-ss.). En este sentido, la afirmación una y otra vez reiterada por Brines de que su poesía es, en verdad, «una extensa elegía» (1995: 24) acuerda con la reformulación observada por Ruiz Pérez, más amplia, en clave tonal, de un género de larga data que, en el caso de Elegías a M. B., se refuerza, no obstante, en su pertenencia genealógica por la elección del título y su consecuente remisión a una antigua tradición funeral².

2 Resulta interesante señalar, asimismo, que este conjunto de homenaje entra en diálogo con el poema de cierre de La última costa (1995), el libro, también último, de la compilación de Tusquets: «Llegábamos exhaustos, con la carne tirante, algo 
El poema primero (Brines, 2010a: 2) que abre esta colección (y que en ella se resignifica) pertenece en realidad a la tercera parte del libro Aún no, de 1971, y enuncia en versos predominantemente largos — dispuestos a la reflexión y el merodeo existencial- el recuerdo de la muerte en dos tempos de una única representación. Es el memento mori como cifra de la poética de Brines el que abre esta plaquette a modo de texto prologal, y aparece entonces como phantasma, representación imaginaria de lo ominoso del vivir, que resulta, en puridad y de acuerdo con Quevedo, una «nueva ejecución» hacia la muerte. La elegía aquí se vuelve, como en toda la poética brineana, hemos dicho, un "tono", pero también una puesta en escena, cuyos «representantes» - los padres, el hijo (sujeto él mismo de la mirada y de la reflexión) — anticipan la previsibilidad de esta comedia humana en un decorado, el natal, repetido a dos tiempos:

Con rostro plateado y hondo olor de naranjo, espera un hombre. $\mathrm{Y}$ una mujer espera, vigilando el jazmín. Son dos extraños.

Miré desde el balcón, y en el balcón no había nadie.

Dionisio Cañas, en el canónico ensayo ya referido sobre el autor, nos alerta claramente acerca de la rotundidad del cambio entre ambas secuencias. En esta "puesta en escena de los tres personajes en presencia», en el segundo segmento «el padre se ha convertido en un hombre y la madre en una mujer, son dos extraños» (1984: 35). «Proyección de extrañeza», continúa diciendo Cañas, que constituye el síntoma inequívoco de la desaparición, una extrañeza no mensurable con los registros de lo temporal y lo espacial, que excede y desestabiliza cualquier posibilidad de registro porque es lo completamente otro, lo que ha quedado del lado de la muerte.

El segundo de los poemas, «Donde muere la muerte» (Brines, 2010a: 3), de extraordinaria belleza, es el primero de los inéditos en el que el fantasma de la muerte toma forma concreta en el cuerpo de «M. B.». A esa muerte, que "en la vida tiene tan solo su existencia», se dedica la larga primera parte del texto, que, como en otros

seca. / Un aire inmóvil, con flecos de humedad, / flotaba en el lugar. / Todo estaba dispuesto. / [...] Mi madre me miraba, muy fija, desde el barco, / en el viaje aquel de todos a la niebla» (Brines, 1999: 533; subrayados nuestros). 
del autor, aborda el motivo desde una perspectiva general, morosa y en apariencia distanciada, aun cuando sus palabras, como «la ceniza», penetren en nosotros, dice Brines, "como un cielo llagado». El final de esta estrofa y la siguiente están dedicados al «dolorido sentir» del hijo recién huérfano y su apóstrofe sin respuesta a una interlocutora ya difusa en la orilla de la completa extranjería. La elegía repone aquí la extensión del memento mori al oficio mismo del vivir, por contraste con el niño que, en la inconsciencia feliz, no percibe aquella genial pero cruenta sucesión metonímica de «pañales y mortaja» expresada por Quevedo:

Fuera del hospital, como si fuera yo recogido en tus brazos, un niño de pañales mira caer la luz, sonríe, grita, y ya le hechiza el mundo que habrá de abandonarle.

Madre, devuélveme mi beso.

El texto titulado «Elegía a M. B.» (Brines, 2010a: 4) insiste en la separación, la extrañeza abierta por la constatación de la pérdida y la necesidad imperiosa de la restitución, que ya no es consolatio religiosa o metafísica, como en la elegía manriqueña o la romántica, sino empecinado ejercicio de la memoria. Como en el poema anterior, persiste la figura clásica del interlocutor in absentia pero también la constatación de la propia desaparición tras el naufragio, en el juego, otra vez quevediano, de los tiempos verbales:

\author{
Salvo, en la red, algún pecio \\ informe, \\ fragmentario, \\ aunque no más que el mío, \\ cuando quiero salvar \\ lo que soy, \\ que es solo lo que fui.
}

La elegía al ausente es también, en realidad, la auto-elegía de quien ya está muerto en el «sumo engaño» de la vida, como ha expuesto Brines con sequedad conceptista en ese extraño libro que fue Insistencias en Luzbel, de 1977. El amor del hijo, la memoria precaria de ese amor y de la palabra que lo retiene son intentos erráticos ante la inminencia apenas consoladora de «un solo y puro / vacío / misterioso. / La sosegada música inaudible» (2010a: 4). Los ecos de Fray Luis y de San Juan de la Cruz son aquí claros e inquietantes. 
No obstante, cuesta pensar que la «no perecedera / música, que es la fuente y la primera» del agustino en su memorable «Oda a Francisco Salinas», o la «música callada» y la «soledad sonora» del carmelita en el Cántico espiritual, sean aquí referentes de una trascendencia posible; más bien, en cambio, los versos finales del poema escenifican una ataraxia en todo laica ante el fin de la vida, «ese paréntesis - ha dicho Brines- entre dos nadas». La eternidad es en verdad "ciega» como se asegura en el texto siguiente, «Un aire en la terraza» (2010a: 6), donde la presencia de M. B. retorna como amable recuerdo. Si aquel bello y triste pedido ante el beso imposible expresaba con reticencia estoica la desesperación por la constatación del final, aquí la intensidad de vida de la ausente se vuelve, en la memoria, una consolación cierta, como cierta es la celebración del instante en la poesía de Brines: aromas, texturas, cuerpos hermosos, tardes doradas por los naranjos y los soles de su tierra natal. Como asegura Francisco Díaz de Castro, en estas elegías «se desplaza la indagación metafisica a un segundo plano para dar mayor protagonismo a la experiencia sensorial», y es justamente en este poema «donde la elegía alcanza el mejor y más emocionante equilibrio entre la intensidad sensorial y la evocación amorosa de la madre» (2011: 50). En esta apuesta compensatoria ingresa M. B.:
Me diste la existencia
y acaso, porque fui,
fue más feliz la tuya.
Hoy se apaga la tarde
con lentitud,
se acerca hasta el vacío;
y el día que se acaba
ha sido muy hermoso.

«La rendija en la sombra» (Brines, 2010a: 7), penúltimo poema de la serie, vuelve como contrapunto al tono sombrío del desamparo y al apóstrofe y las interrogaciones retóricas (ubi sunt?) por un sentido sobre el que nadie responde. Relojes detenidos, una casa vacía, la neblina de fondo, sonidos monocordes, marcan la condición de «espectro de la vida que amamos», la extranjería de los padres ausentes. El final da cuenta de esa implacable mirada barroca sobre la desaparición propia y ajena en la percepción de la continua despedida, por lo que el canto «élego» vuelve con insistencia quevediana 
a jugar entre lo general y lo particular, excediendo una muerte puntual para cantar todas las muertes:

Despoblados los tres

- yo rezagado-

las sombras no serán.

Ni la luz, ni el vacío.

¿Hasta cuándo ahí el mundo?

El breve texto último cierra el trayecto en claroscuros de este también breve poemario, bajo el título de «Reencuentro» (2010a: 8). El retorno a la casa de Elca en el presente en completa soledad se anima por el recuerdo, la pervivencia de la Arcadia infantil y familiar en un amor constante más allá de la muerte. Las desapariciones puntuales, los viajes definitivos, no parecen interferir ahora en esa unión amorosa que transgrede la materialidad (y la desmaterialización) de los cuerpos para ser ella misma una existencia alternativa en la memoria, el único y posible lugar de la restitución desde la melancolía barroca:

[...] no sé en qué año estoy

y han salido mis padres de la casa

con los brazos abiertos,

me besan,

les sonrío,

me miran

y de nuevo les beso.

—y están muertos-

Pero hay algo más, por lo que la memoria no constituye por sí sola el locus exclusivo de esta consolatio moderna. En la elegía amorosa latina y también en los lamentos elegíacos de la poesía áurea, el nombre de la amada es sustituido, se dice que por convenciones pragmáticas, por un nombre poético: desde Lesbia hasta Filis y Amarilis, sin olvidar a la más dura que mármol a sus quejas y pasando por la Luz platónica de Herrera, la tópica del planto y la «memoria del bien perdido" ha hecho del nombre poético un ejercicio privilegiado de reencuentro. Un libro cercano a Brines por tiempo y por compañía generacional, No amanece el cantor, publicado por José ÁngelValente en 1992, en memoria de su hijo Antonio, muerto trágicamente en 1989, repone, en esa desolada elegía, el nombre poético — «Agone», ya presente en libros anteriores- como un gesto 
de afirmación y de confianza regenerativa en la palabra. La escritura de un nombre sustraído de la mera designación civil, y, por lo tanto, histórica y mortal, permite al presente y al ausente ingresar en esa esfera atemporal de una existencia otra, cuya garantía de subsistencia está dada por los signos memorables que la trazan. En esta misma eternidad sin dioses perdura María Bañó en la mención de «M. B.». Más allá del gesto austero y pudoroso del hijo dolorido, que esconde el nombre real para sustraerse de aquella falacia patética de la que abjurara Cernuda, nos parece que hay aquí, como en Valente, y como en toda la tradición mencionada en sus múltiples acordes, el intento de trascender el nombre y el cuerpo reales burlando todas las muertes con el único instrumento que la voz dolorida tiene a su alcance: el mundo posible y cierto de la literatura, ahora y siempre, más perenne que el bronce.

\section{DONDE MUERE LA MUERTE}

A la espera de Donde muere la muerte, que lleva el título de uno de los poemas de la plaquette abordada, analizaremos los sueltos recogidos por los diversos estudios y antologías precedentes: «Mi resumen», «El vaso quebrado» $\mathrm{y}$ «Mis tres fauces» (Para quemar la noche, de Francisco Bautista, 2010); «Trastorno en la mañana», «Luzbel, el ángel», «Mis tres fauces», «Donde muere la muerte» $\mathrm{y}$ «El vaso quebrado» (Yo descanso en la luz, de Luis García Montero, 2010); «Trastorno en la mañana», «Luzbel, el ángel», «Mis tres fauces», «Donde muere la muerte», «El vaso quebrado», «Elegía a M. B.», «Reencuentro», «Un aire en la terraza», "La rendija en la sombra» (estos cuatro últimos recogidos en la mencionada plaquette de 2010, previamente analizada) y «Mi resumen» (Jardín nublado, de Juan Carlos Abril, 2016); «Mi resumen», «Mis tres fauces», «Luzbel, el ángel», «Trastorno en la mañana» $\mathrm{y}$ "El vaso quebrado» (Una obstinada imagen. Políticas poéticas en Francisco Brines, mi estudio y antología de 2016); «Brevedad de la vida», "Trastorno en la mañana», «La manzana imaginada», «Luzbel, el ángel», «Conjetura de una salvación», «El vaso quebrado», «Un frío demente», «Mis tres fauces», «Mi resumen» $\mathrm{y}$ «El último viaje», todos ellos presentados dentro del «libro inédito» Donde muerte la muerte, diseñado por el propio Brines (Entre dos nadas. Antología consultada. 1959-2017, de Alejandro Duque Amusco, 2017) y que tomaremos como versión definitiva para nuestras indagaciones. Finalmente, 
Desde Elca (enero de 2021), última antología del autor, prologada por Fernando Delgado, contiene el inédito «El testigo» (que no debe confundirse con un texto anterior, homónimo, de Aún no, de 1971), incorporado a nuestro análisis.

En estos textos, como en Elegías a M. B., asistimos a la contracción de un estilo que, en otros libros, impulsaba el poema de largo aliento, solidario de una meditación poblada de meandros y caminos alternativos, facilitada, asimismo, por la naturaleza expansiva de los endecasílabos sueltos.Ahora, en este ejercicio - que es estético tanto como vital-, Brines insiste en los temas de siempre, pero llevados al mínimo en su resolución formal y gráfica, una autodepuración cuya austeridad prevé la despedida, el silencio final. Como dice Díaz de Castro, el autor va apostado por «una creciente reflexión ética en tono menor, el único posible para hacer comunicable, sin excesos retóricos, la energía de la búsqueda, la permanente tensión entre el agradecimiento a la existencia y el dolor de la pérdida» (2011: 48), ya evidente, para el crítico, en el «registro testamentario» de $L a$ última costa (1995).

Los textos reunidos por Duque Amusco en Entre dos nadas se abren con un poema en prosa («inédito completo», indica el editor, junto con «Mi último viaje») que, justamente, se autopercibe como testamento y síntesis de un proyecto creador en las vías de su clausura. "Brevedad de la vida» (Brines, 2017: 319-320), así titulada, es, no obstante, un texto extraño, diverso de los otros a los que nos ha acostumbrado el autor. Las cuatro primeras oraciones disparan en presente una escena, en sentido cinematográfico, poblada de un intenso desasosiego que rompe con la gramática del tono brineano habitual: «Un suspiro que alienta y se acongoja. Se oscurece el relámpago, sin apenas lucir.Viento presto engolfado en la calma, sin tiempo a respirar; blanco interpuesto de inmediato a la flecha: violencia violencia». El quevediano «vivir» como "principio del morir» es un movimiento sin término acelerado por gerundios que van del "prólogo» al "epilogando» (un uso admitido, pero excéntrico en un escritor tildado como "clásico») y también la mudez compensada por el superlativo de las lágrimas «caudalísimas» $\mathrm{y}$ «de sombra». «Respiración», «ceniciento suspiro», la "violencia violencia» antes citada que obtura el paso del aire en la garganta y en la escritura, se vuelven significantes de un discurrir agónico tras lo cual se reflexiona, al acabar el primer párrafo: «Toda la vida cabe en un paréntesis [entre dos nadas] que choca y cierra en signo cóncavo, 
la vida arremetida. Esta es nuestra experiencia». Tras esa secuencia desolada, la segunda y última pone en evidencia cabalmente esa tensión tan característica y fecunda de Brines entre pérdida y goce del vivir, en este caso traducida en la afirmación de una vocación: la creencia juanramoniana del quehacer poético como «trabajo gustoso", base del idealismo krausista en relación con el progresivo mejoramiento de la humanidad. Si la rosa «es símbolo de brevedad», también "es consuelo porque aroma», e igualmente lo es la carne "de confortante olor, olor que se desprende del trabajo que agrada, pues el hombre sólo se cumple en el amor que acompañe al trabajo", en el que «la vocación más honda [es] la amorosa». Tal el compromiso ético y humanista que Brines ha venido sosteniendo desde siempre, su "política poética» (para seguir aquí invocando a su maestro de Moguer) y su ethos docente, que encuentra en el lector la complementación "cordial» (querría Machado) y la justificación de una obra, de una vida, el cumplimiento de su voluntad final: «Lector, tú eliges tus poetas. Espero que tu sombra me aloje. Es solo mi deseo, porque tan solo así sabré saberme sido»³.

El lector como interlocutor preferencial de «Brevedad de la vida» cede su lugar al sujeto como lector él mismo en el extraordinario «Trastorno en la mañana» (2017:321), siguiente poema de la serie: “¿Qué sucede en los pinos, las palmeras? / He leído el poema de un amigo / y se han puesto a cantar todos los pájaros. / Lo leía en voz alta / y ellos sonaban con sus cantos de otros siglos». Texto de una intensidad vital condensada y precisa, donde «el poema [...] suena como un pájaro / y es también flor». La literatura como "forma de la felicidad» (según decía Borges) es el «trastorno» impensado de esta mañana plena de cantos, luces y aromas: en pocos versos, el Brines gozoso que aúna el amor por las palabras y el amor por la naturaleza recupera en el sentido del «canto» y del "pájaro» lo esencial poético (Juan Ramón, nuevamente, y aún quizá también los pájaros

3 Muchos son los textos referidos al lector, ya estudiados en otros lugares (Romano, 2016). Me interesa aquí volver a "La tarde imaginada», hacia el final de La última costa (Brines, 1999: 529), donde los tiempos de la escritura y la lectura se sobreimprimen en la autoconciencia del "poema haciéndose». «La tarde imaginada» hecha de "palabras espectrales» reencuentra en el lector su alternativo y eficaz complementario en quien la voz deposita la esperanza de nombrar y nombrarse, con el reiterado «olor de la rosa» referido en el poema analizado: «¿Y a mí, quién podría salvarme? / ¿Tus ojos, que ahora crean mi tarde inexistente? / Lector: esfuérzate y enciéndela: / está donde un olor de rosa te llega del camino. / Si existo es porque existes». 
de otras músicas calladas). En esta línea de reflexión metapoética se encuentra «El vaso quebrado» (2017:327), dedicado inicialmente a sus queridos poetas comarcanos Carlos Marzal y Vicente Gallego y quizá también al conspicuo alter ego que habitó tantos de sus diálogos. Allí, el maestro Brines escribe desde su umbral (o su abismo) otra propuesta, en un poema breve y de severa retórica que entrega a sus discípulos (y a sí mismo) como herencia y camino a seguir. Una suerte de "punto cero» a partir del cual sea posible asistir a un nuevo y depurado nacimiento del «canto»: «quiero decir que dejes / las palabras gastadas, bien lavadas, / en el fondo quebrado / de tu alma, / y que, si pueden, canten».

Un poco más extenso, y mucho menos esperanzado, «La manzana imaginada» (2017: 322-323) nos recuerda títulos anteriores como el ya citado «La tarde imaginada» (La última costa, 1995) y aquel célebre colofón de «Desde Bassai y el mar de Oliva» (El otono de las rosas, 1986): "Yo sé que olí un jazmín en la infancia una tarde, y no existió la tarde» (Brines, 1999: 458). La intensidad de la existencia se fragua al modo romántico en el juego entre la mirada del poeta y lo real, en la imagen creadora que predicaba Coleridge a través de la metáfora de la "lira eolia»", y, complementariamente, en la imagen recobrada y construida en la memoria sensorial, eje del texto que analizamos ${ }^{5}$ : «Recuerdo, hace ya un tiempo, que imaginé aquella manzana / pues me vino su olor, / su tersura rosada me suavizó la yema de los dedos, / y al morder en su carne / me regresó a la infancia». La imagen inicial se difiere en sucesivos actos del rememorar (como el minucioso recorrido de la mano que toca, que acaricia morosamente frutos y amores) hasta arribar de la plenitud positiva a la "acidez acorchada de este día en que escribo». Es esa imagen, su recuerdo, esa manzana, el resumen agrio y dulce «de mi vida». Lo mismo acontece con el cuerpo escondido del presente

4 En un estudio indispensable, es Meyer Abrams quien refiere esta armonización sujeto-objeto, base de la teoría de Coleridge esbozada en su Biographia Literaria de 1817: «La lira eolia es el poeta y el poema es el acorde musical que resulta de la acción recíproca de los elementos internos y externos, del viento cambiante y la constitución y tensión de las cuerdas» (1975: 96).

5 Remito a José Luis Gómez Toré (2002: 261-ss.), quien hace un excelente abordaje de esta cuestión. Por su parte, Brines le explica en una entrevista a Sanz Villanueva, respecto de ese verso, que «no existió la tarde porque mi vida va a dejar de existir, pero mi vida estuvo. [...] yo sé que viví. Que fue placentera e intensa aquella vida. "Y no existió la tarde" porque todo se acaba" (Brines en Sanz Villanueva, 2008: 15). 
«envejecido»: "en el espacio abierto donde respira el ojo, se me ha tornado el cuerpo / de carne antecedida, / y otro cuerpo desnudo, / junto al mío, y más joven / [...] palpitaba suavísimo, escondido». La remisión a la propia "carne antecedida» y a la comunión amorosa, que acompañan el tacto y el ojo respirante, una sensorialidad con vida propia, proliferante como la imaginación romántica, expandida en espiral desde aquella manzana — infancia, mediodía, ácido presente- hasta los pliegues del deseo erótico, deriva, finalmente, en la naturaleza. El mar, el campo, la ventana de Elca, completan, en la última estrofa del poema, la cartografia de una obra total: «He mirado hacia el mar, el balcón lo enmarcaba, y he cruzado los campos». No obstante, ese ir y volver en continuado - en el que la escritura produce y reproduce, deja «huellas» de lo vivido, lo recordado, lo imaginado, con un empecinamiento que la vuelve precaria salvación- retrasan «la partida final» de otras dos imágenes posibles, la suya propia y la del lector, destinadas ambas a la fatal desaparición: «Después te borrarás con el olvido de ellas».

«Luzbel, el ángel» (Brines, 2017:324-325) retorna, por su parte, a uno de los mitos más potentes y singulares de la poética brineana, «la nada manchada por la vida», el "negro Caballero del Olvido», cuyas resonancias bíblicas no han estado protagónicamente en la base hermenéutica de esta teología negativa pero la inspiran, y que aquí vuelven representadas haciendo foco en una erótica mística invertida ante la magnificencia del rebelde, perfil de los muchos e inquietantes Satanes de la literatura y del arte. Frente a la luz unívoca de lo absoluto inhallable ${ }^{6}$, aquí el sujeto negocia con Luzbel su propia rebeldía. «Si la carne es Satanás / le amo», dice, y tras esa afirmación se elabora en el poema un espacio de encuentro, un locus amoenus del amor inspirado en el sensorium del Cantar de los Cantares con el signo de lo joven, lo bello y, especialmente (por ello, la inversión), lo «impuro». El pacto con el diablo anida en una lírica de supervivencia que toma de los viejos modelos la emergencia siempre rebelde de los cuerpos, aquí extremada, indómita ante las

A propósito de Insistencias en Luzbel (1977) acierta en su análisis Francisco José Martín al asegurar que «insistir en Luzbel es negarse a la engañosa claridad del fundamento, buscar en el reverso de la luz detrás del orden impuesto [...]. Quizá haya que buscar aquí la raíz de esa lucidez [...] en la poesía de Brines: un fuerte deseo de otra luz, la convicción plena del engaño de la luz que se impone desde los cielos. Luzbel no es el mal o el pecado, sino lo derrotado por la luz. Lo que se rebela ante la luz, ante su poder totalitario» (1998: 63). 
imposiciones de la biopolítica y de la heteronorma: «El firmamento tiembla, / y en él nos penetramos. / Mi cuerpo, ya vencido / por la edad importuna, / se hace prado en el río, / atardecer suavísimo.Y él pace». Es el encuentro amoroso, el goce de la carne, uno de los absolutos innegociables de una vida y de una poética ${ }^{7}$. Por eso, no extraña que en el mencionado "El testigo», editado en la recopilación titulada Desde Elca (2021), el otro Dios (siempre dormido, ciego o borracho, como en Borges y en Cernuda) sea homologado con el sinsentido y la vanidad de la existencia: «¿Quién pone en nuestra mente / la incógnita de Dios? / Él es Amigo y Enemigo. / Es el nombre otorgado a la ignorancia. Su aletazo nos borra. / Nada he sido» (Brines, 2021: s. p.).

La asociación de ambos textos con "Mis tres fauces» (Brines, 2017: 330-331) es inmediata. Las «tres fauces [...] del animal que soy» y que entre sí se lastiman escenifican una contienda de entidades negativas: «restos de espíritu y de carne», aullando ante un «Dios (que me abandona)». Como asegura Andújar Almansa en su finísimo análisis del poema, este perro es «uno de los símbolos más estremecedores imaginados por Brines para insistir en la desolada condición humana» (2011:51) y al que el autor había ya abordado en "Aullidos y sirenas», de El otoño de las rosas (1986): el aullido como grito inarticulado en el límite de lo decible y de lo significable, la animalidad post (anti) humana también presente en el poema inmediatamente anterior en el orden de esta recopilación, «Un frío demente» (Brines, 2017: 328-329), donde «aúlla un perro viejo, / y el viento derrama su dolor en el vacío». Este «rugiente estío» (2017: 328) destempla las premisas hondamente humanistas, en el sentido clásico, de nuestro autor, a través de un ethos y de un tono otros asomados al abismo y a la «náusea» brutal de la pura contingencia existencialista. La analogía del perro establece, por lo demás, en esta serie de inéditos, una correlación con la propia animalidad de Luzbel, representado desde la Edad Media como el macho cabrío que desconoce el mandato del Pastor. Pero también, en su hondura barroca y romántica, Luzbel es, por encima del rebelde, el melancólico de Milton (Praz, 1969 [1948]: 83), el ángel caído, el despreciado

Brines le dice a Duque Amusco: «Hay dos cosas que me han dado consolación, que es esa infancia feliz, que pude no haber tenido, y, luego, la existencia del amor que, aunque haya acabado, existió con toda su plenitud, en toda su integridad. Cuando yo pensaba cómo puede ser el "más allá”, decía: "Esto, pero sin acabar"» (Brines en Duque Amusco, 2021: 53). 
por Dios, como el Jesús crucificado que clama al Padre abandónico: "Yo soy ahora el perro, que aún no ha muerto, / y soy también el miedo de Cristo abandonado / en el viejo olivar, / bajo los astros fríos». A partir de estas correspondencias, que articulan un universo profundamente ajeno al padecer humano, «Brines ha escrito - nos dice acertadamente Andújar Almansa (2011: 52) con referencia a «Mis tres fauces»- el poema de nuestra noche de Getsemaní».

«Conjetura de una salvación» (Brines, 2017: 326), por su parte, pretende reparar, aunque siempre desde la duda y el lugar de la incerteza, tan características de esta poesía "del pensamiento», el vacío de esa «negra luz / que aposenta la Ausencia». El recuerdo de los días de plenitud y epifanía de lo eterno se desatan con una pregunta que corporiza «el pequeño dios» (el único posible) ofrecido por la infancia, el amor, la naturaleza. En esta poética del tanteo y del ensayo, la "conjetura» permanece en la estrofa de cierre, destinada como tantas veces a un doble interlocutor (el otro, el mismo), el complementario humano con quien se establece, desde la comunión de iguales, esa "salvación», ese diálogo emitido en un desierto y ante un Silencio compartidos: «Las palabras que lees, ¿a quién hablan, si mi verdad y la tuya son las mismas?».

Brevísimo como su título, y ya llegando al final del libro, «Mi resumen» (2017:333) muestra la desolación de una voz ubicua, de una imagen borrada "que se asoma a un espejo / que no refleja a nadie». La concisión y seca austeridad del epitafio como género funeral se hace todavía más explícita por la concurrencia complementaria del género del «resumen», una insistencia plasmada en el primer verso entrecomillado, «Como si nada hubiera sucedido». Deliberadamente, Brines tomó por fortuna la decisión de no clausurar este proyecto de libro con el poema referido, al que continúa, como punto final, «El último viaje» (2017: 334-336) ${ }^{8}$, del todo emparentado con «La última costa», el mencionado texto de cierre del poemario homónimo de 1995: «Desde la barca, serio, tan solo tú fijabas la mirada» (2017: 334). Sin embargo, en el discurrir del sujeto hacia la nada - la propia y la de todos- («Y que sea el Silencio», reza el verso final), aparecen en ese pesado equipaje, aligerándolo, referentes de un vitalismo con el que ahora sí nos satisface — por justa— la despedida primera; se trata, pues, de un inédito absoluto con el que el poeta ha querido cerrar esta antología de su obra» (2017: 334). 
de esta obra notable. Así, la naturaleza en su esplendor: «el río / fluía entre las luces / de aquel atardecer / repleto de palomas / laureles y morados»; los jóvenes, tantas veces mirados y poetizados como epítome de la plenitud vital: «Y cerca de la orilla / divisé a aquellos jóvenes / jugando a la pelota»; el recuerdo de la felicidad, en una ambigua alusión que remite quizá doblemente al paisaje de la infancia y a los cuerpos del amor: «Y un cuerpo fantasmal / habitó en otro tiempo / aquel pequeño prado / en que, fuera de ti, / a nadie conocías». A un lado y a otro, la muerte inminente y la vida que prosigue, «la vida que amé / como el don de un dios bueno». En la «opaca intensidad» de este lado del camino se ha construido esta poesía total, con la humildad de quien, sabiendo que todo está próximo "ya a cesar», nos la ofrece como testimonio y ejemplo de insistencia, de persistencia y, sobre todo, de resistencia. Entre las dos nadas ha estado todo, y la vida y la obra de Francisco Brines, entonces, constituyen para nosotros, sus lectores, ese "don de un dios bueno" que permanece en la belleza de su poesía y en la generosidad de su inagotable magisterio. 


\section{BIBLIOGRAFÍA}

Brines, Francisco (1999). Ensayo de una despedida. Poesía completa (1960-1997), Barcelona, Tusquets.

— (1995). «La certidumbre de la poesía», en Francisco Brines, Selección propia, Madrid, Cátedra, pp. 13-53.

— (2010a). Elegías a M. B., Málaga, Centro Cultural Generación del 27.

— (2010b). Yo descanso en la luz.Antología, ed. Luis García Montero, Madrid,Visor.

- (2010c). Para quemar la noche, introducción, edición y selección

de Francisco Bautista, Salamanca, Universidad de Salamanca.

— (2016). Jardín nublado. Antología poética, ed. Juan Carlos Abril,Valencia, Pre-Textos.

— (2017). Entre dos nadas. Antología consultada. 1959-2017, prólogo y

edición de Alejandro Duque Amusco, Sevilla, Renacimiento.

— (2021). Desde Elca (Antología), prólogo de Fernando Delgado,Valencia, Pre-Textos.

Abrams, Meyer (1975). El espejo y la lámpara. Teoría romántica y tradición crítica, Barcelona, Barral.

Andújar Almansa, José (2003). La palabra y la rosa. Sobre

la poesía de Francisco Brines, Madrid, Alianza.

_ (2011). «Un poema de Francisco Brines», Ínsula. Revista de Letras y Ciencias

Humanas [«Un mismo tiempo para dos poéticas: Caballero Bonald y Brines», coords.

Luis García Montero y Juan Carlos Abril], 775-776, julio-agosto, pp. 51-52.

Cañas, Dionisio (1984). «La mirada crepuscular: Francisco Brines», en Poesía y percepción (Francisco Brines, Claudio Rodriguez y José Ángel Valente), Madrid, Hiperión, pp. 23-81.

Díaz de Castro, Francisco (2011). «Sobre la poesía última de Francisco Brines», Ínsula. Revista de Letras y Ciencias Humanas [ «Un mismo tiempo para dos poéticas: Caballero Bonald y Brines», coords. Luis García Montero y Juan Carlos Abril], 775-776, julio-agosto, pp. 48-50.

Duque Amusco, Alejandro (2021). «Ningún hombre es feliz. Una conversación con Francisco Brines», Clarín. Revista de Nueva Literatura, 151, pp. 49-54.

García Gibert, Javier (2010). La «humanitas hispana». Sobre el humanismo literario en los Siglos de Oro, Salamanca, Universidad de Salamanca.

Gómez Toré, José Luis (2002). La mirada elegíaca. El espacio y la memoria en la poesía de Francisco Brines, Valencia, Pre-Textos.

López Bueno, Begoña (1996). «De la elegía en el sistema poético renacentista o el incierto devenir de un género", en Encuentros Internacionales sobre poesía del Siglo de Oro español. La elegía, ed. Begoña López Bueno, Sevilla, Universidad de Sevilla, pp. 133-166. 
Martín, Francisco José (1998). El sueño roto de la vida (Ensayo sobre la poesía de Francisco Brines), Alicante, Aitana.

Praz, Mario (1969 [1948]). «Las metamorfosis de Satanás», en La carne, la muerte y el diablo (en la literatura romántica), Caracas, Monte Ávila, pp. 75-103.

Romano, Marcela (2016). Una obstinada imagen. Políticas poéticas en Francisco Brines, Villa María (Córdoba), EDUVIM (Universidad Nacional de Villa María).

— (2017). "Querula voce: el ethos elegíaco en José Agustín Goytisolo», en Buenos Aires - Madrid - Buenos Aires. Homenaje a Melchora Romanos, comps. Florencia Calvo y Gloria Chicote, Buenos Aires, Eudeba, pp. 577-587. Ruiz Pérez, Pedro (1996). «El discurso elegíaco y la lírica barroca: pérdida y melancolía», en Encuentros Internacionales sobre poesía del Siglo de Oro español. La elegía, ed. Begoña López Bueno, Sevilla, Universidad de Sevilla, pp. 317-367. Sanz Villanueva, Santos (2008). «El don de vivir: paréntesis entre dos nadas. Conversación con Francisco Brines», Campo de Agramante, 9, primavera-verano, pp. 5-34. Siles, Jaime (2002). «Francisco Brines, un clásico viviente», Nueva Revista de Política, Cultura y Arte, 80, marzo-abril. [En línea: http://europa.sim.ucm. es/compludoc/GetSumario?r=/S/10204/11300426_1.htm\&zfr=0]

Williams, Raymond (2000). Marxismo y literatura, Barcelona, Península. 